Article

\title{
Bio-Control of Salmonella Enteritidis in Foods Using Bacteriophages
}

\author{
Hongduo Bao ${ }^{1, \dagger}$, Pengyu Zhang ${ }^{2, \dagger}$, Hui Zhang ${ }^{1}$, Yan Zhou ${ }^{1}$, Lili Zhang ${ }^{1}$ and Ran Wang ${ }^{1, *}$ \\ ${ }^{1}$ Institute of Food Safety, Jiangsu Academy of Agricultural Sciences, State Key Laboratory Cultivation \\ Base of MOST- Jiangsu Key Laboratory of Food Quality and Safety, Nanjing 210014, China; \\ E-Mails: baohongduo@163.com (H.B.); zh851200@163.com (H.Z.); \\ zhou.yan.77@hotmail.com (Y.Z.); lilizhangnj@163.com (L.Z.) \\ 2 Ginling College, Nanjing Normal University, Nanjing 210097, China; \\ E-Mail: panpan.jump@163.com \\ ${ }^{\dagger}$ These authors contributed equally to this work. \\ * Author to whom correspondence should be addressed; E-Mail: ranwang@ jaas.ac.cn; \\ Tel.: +86-25-84391627.
}

Academic Editor: Abram Aertsen

Received: 29 April 2015 / Accepted: 17 August 2015 / Published: 24 August 2015

\begin{abstract}
Two lytic phages, vB_SenM-PA13076 (PA13076) and vB_SenM-PC2184 (PC2184), were isolated from chicken sewage and characterized with host strains Salmonella Enteritidis (SE) ATCC13076 and CVCC2184, respectively. Transmission electron microscopy revealed that they belonged to the family Myoviridae. The lytic abilities of these two phages in liquid culture showed $10^{4}$ multiplicity of infection (MOI) was the best in inhibiting bacteria, with PC2184 exhibiting more activity than PA13076. The two phages exhibited broad host range within the genus Salmonella. Phage PA13076 and PC2184 had a lytic effect on $222(71.4 \%)$ and 298 (95.8\%) of the 311 epidemic Salmonella isolates, respectively. We tested the effectiveness of phage PA13076 and PC2184 as well as a cocktail combination of both in three different foods (chicken breast, pasteurized whole milk and Chinese cabbage) contaminated with SE. Samples were spiked with $1 \times 10^{4} \mathrm{CFU}$ individual SE or a mixture of strains (ATCC13076 and CVCC2184), then treated with $1 \times 10^{8} \mathrm{PFU}$ individual phage or a two phage cocktail, and incubated at $4{ }^{\circ} \mathrm{C}$ or $25^{\circ} \mathrm{C}$ for $5 \mathrm{~h}$. In general, the inhibitory effect of phage and phage cocktail was better at $4{ }^{\circ} \mathrm{C}$ than that at $25^{\circ} \mathrm{C}$, whereas the opposite result was observed in Chinese cabbage, and phage cocktail was better than either single phage. A significant reduction in bacterial numbers (1.5-4 log CFU/sample,
\end{abstract}


$p<0.05)$ was observed in all tested foods. The two phages on the three food samples were relatively stable, especially at $4{ }^{\circ} \mathrm{C}$, with the phages exhibiting the greatest stability in milk. Our research shows that our phages have potential effectiveness as a bio-control agent of Salmonella in foods.

Keywords: Salmonella Enteritidis (SE); phages; phage cocktail; food; bio-control

\section{Introduction}

Salmonella is a gram-negative bacterium that is one of the principal causes of food-borne diseases. Presently, over 2500 serotypes of Salmonella are known [1], and the most common worldwide is Salmonella Enteritidis (SE) [2]. SE is a food-borne pathogen that is a significant food safety concern globally. Since the period 1996-1999, the recorded incidence of human SE infection in the Foodborne Diseases Active Surveillance Network (FoodNet) has increased by 44\% [3]. In Canada, SE was detected in various commodities, most frequently in chicken (with PT13, PT8 and PT13a predominating) [4]. In China, Ke's study of 1764 clinical Salmonella enterica isolates in Guangdong province showed that $\sim 15 \%$ of isolates were SE, which was the primary cause of salmonellosis in adults [5]. Despite improved preventive and control strategies in chicken commercial flocks and in the food industry, SE infection still poses a constant problem [6-9]. Moreover, with the misuse of antimicrobials in many farms including disease treatment and growth promotion in domestic livestock, many SE are resistant to several antimicrobial agents.

New environmentally-friendly intervention strategies are needed to treat microbial infection. In recent years, applications of bacteriophages to control bacterial pathogens have received new interest [10]. They have also been identified as a prospective alternative bio-control method for infections and contaminations by antimicrobial resistant pathogens [11]. Bacteriophages, or phages, are abundant in the environment, with an estimated ratio of 10:1 to their bacterial hosts. In many experimental studies, phages have been used to control Salmonella contamination in a variety of foods. Goode et al. [12] used phages to well-control SE on chicken skin that had been inoculated with commercially relevant numbers of bacteria (i.e., $1 \log \mathrm{CFU} / \mathrm{cm}^{2}$ ) . In Leverentz's study [13], Salmonella-specific phage could reduce Salmonella numbers in experimentally contaminated fresh-cut melons and apples stored at various temperatures. They also found that a phage mixture was better in reducing Salmonella populations than chemical sanitizers on honeydew melon slices [13]. The Salmonella phage (Felix-O1), which has a broad host range within the genus Salmonella, demonstrated an approximately about 2 log units reduction in Salmonella Typhimurium DT104 inoculated on chicken frankfurters [14]. In addition, phages had successfully controlled the growth of other important pathogens such as Listeria monocytogenes [15,16], Escherichia coli O157:H7 [17,18], and Shigella [19].

Our study involved the isolation from chicken excretion sewage of two new lytic SE phages using SE ATCC13076 and CVCC2184 as hosts. We determined their host ranges and lytic activity against hosts in vitro. The major aim of this study was to evaluate the potential of the two individual phages, or a mixture of the two (cocktail), to control SE contamination in three kinds of foods. 


\section{Materials and Methods}

\subsection{Salmonella Cultures, Media and Growth Conditions}

A total of 311 epidemic Salmonella spp. strains were used in this study. Some of the strains were kindly donated by Guoxiang Cao (Chinese Academy of Agricultural Sciences, Yangzhou, China), Guoqiang Zhu (Yangzhou University, Yangzhou, China), Yuqing Liu (Shandong Academy of Agricultural Sciences, Jinan, China), Yanbing Zeng (Jiangxi Academy of Agricultural Sciences, Nanchang, China) and Jiansen Gong (Poultry institute, Chinese Academy of Agricultural Sciences, Yangzhou, China). The others were isolated between 2010 and 2015 from chicken farms and foods by our laboratory and stored in our lab. Of these, $S$. Enteritidis (SE) ATCC13076 and CVCC2184 were used to isolate bacteriophages. They were grown at $37{ }^{\circ} \mathrm{C}$ in Luria-Bertani broth (LB, Beijing land bridge technology Co., LTD, Beijing, China) or LB supplemented with $1.5 \%$ agar.

\subsection{Isolation and Purification of Lytic Salmonella Phages}

Fifty chicken excretion sewage samples were collected from 10 chicken farms in Jiangsu Province, China. Then these samples were used to isolate Salmonella phage as previously described [20]. Phages were propagated on SE ATCC13076 and CVCC2184 using LB (0.6\% agar) soft agar overlays [21]. Incubating the double-layer agar plates for a longer period of time (3-4 days), the host cells that survive in the middle of the plaque were surveyed for whether they are resistant strains or lysogens.

To prepare high titers of phage, crude phage lysate propagating using a single plaque with its hosts was filtered a $0.22 \mu \mathrm{m}$ filter, then $\mathrm{NaCl}(0.5 \mathrm{M}$, final concentration) and polyethylene glycol (PEG 8000) (10\%, final concentration) (Amersco, Solon, OH, USA) were added to the supernatant and incubated overnight at $0{ }^{\circ} \mathrm{C}$. Finally, phage particles were precipitated by centrifugation $\left(10,000 \times g, 15 \mathrm{~min}, 4{ }^{\circ} \mathrm{C}\right)$, and resuspended in $\mathrm{SM}$ buffer $\left(5.8 \mathrm{~g} / \mathrm{L}\right.$ of $\mathrm{NaCl}, 2.0 \mathrm{~g} / \mathrm{L}$ of $\mathrm{MgSO}_{4}, 50 \mathrm{~mL} / \mathrm{L}$ of $1 \mathrm{M}$ Tris, $\mathrm{pH} 7.5,5 \mathrm{~mL} / \mathrm{L}$ of presterilized $2 \%$ gelatin). The final concentration was $1.0 \times 10^{10} \mathrm{PFU} / \mathrm{mL}$.

\subsection{Morphology of the Isolated Phages}

Freshly-purified phage suspended pellets in SM buffer were used in this experiment. A small drop of phage was loaded onto a carbon-coated copper mesh grid and excess phage suspension was removed with filter paper. Negative staining of phages with $1 \%(w / v)$ phosphotungstic acid and phage images were obtained by a Transmission Electron Microscope (TEM) (H-7650, Hitachi High-Technologies Corporation, Tokyo, Japan) at an acceleration voltage of $80 \mathrm{kV}$.

\subsection{Thermal and $\mathrm{pH}$ Stability}

For thermal-stability testing, tubes with phages were kept in a water bath ranging from 30 to $90{ }^{\circ} \mathrm{C}$ for $30 \mathrm{~min}$ or $60 \mathrm{~min}$. For $\mathrm{pH}$-stability testing, samples of phages were mixed in a series of tubes containing buffer peptone water (BPW) of different $\mathrm{pH}$ (adjusted using $\mathrm{NaOH}$ or $\mathrm{HCl}$ ) and incubated for $2 \mathrm{~h}$ at $37^{\circ} \mathrm{C}$. Bacteriophage titers were all determined using the double-layer agar plate method. 


\subsection{In Vitro Experiment of Phage Mediated Lysis}

Overnight cultures of Salmonella ATCC13076 and CVCC2184 were diluted to $\sim 10^{4} \mathrm{CFU} / \mathrm{mL}$ in fresh medium. A single phage stock (PA13076 or PC2184) was added to give three multiplicity of infection (MOI) of $10^{2}, 10^{3}$ and $10^{4}$, respectively. The mixtures were then incubated at $37^{\circ} \mathrm{C}$ for $5 \mathrm{~h}$ with gentle shaking. Phage-free culture (containing only bacteria) and bacteria-free culture (containing only phage) were also included as controls. Bacterial counts were determined at $0,0.5,1,2,3,4$ and $5 \mathrm{~h}$.

\subsection{Host Ranges of Phage}

Three hundred eleven strains of epidemic Salmonella spp. were used in this study. Host ranges of phage were determined by spot test. The method was spotting $10 \mu \mathrm{L}$ of phage preparation $\left(\sim 10^{8} \mathrm{PFU} / \mathrm{mL}\right)$ on lawn cultures of the bacteria strains. Plaque formation was monitored after incubation at $37^{\circ} \mathrm{C}$ for $24 \mathrm{~h}$.

\subsection{Food Sample Preparation}

Three different kinds of foods were purchased at local supermarkets and included: chicken breast, pasteurized whole milk and Chinese cabbage. All food samples were preliminarily analyzed to check for the possible natural contamination by Salmonella, according to the standard procedures. Samples of chicken breast were sliced aseptically into $2 \mathrm{~cm} \times 2 \mathrm{~cm}$ squares (about $1 \mathrm{~g}$ ), and placed into Petri dishes. Pasteurized whole milk samples were divided into $1 \mathrm{~mL} / \mathrm{sample}$ in a biosafety cabinet. Chinese cabbage was washed with water, followed by washing with sterile water and $75 \%$ ethanol, prior to its use in the assays. The sanitized cabbage samples were then sliced into $2 \mathrm{~cm} \times 2 \mathrm{~cm}$ squares, and placed in Petri dishes.

\subsection{Individual Phage Treatment of Their Respective Hosts}

SE ATCC13076 and CVCC2184 were grown individually in LB at $37^{\circ} \mathrm{C}$ overnight. Phages PA13076 and PC2184 were used individually to challenge their appropriate hosts which were added to the three kinds of foods. Experiments were conducted at two temperatures $\left(4\right.$ or $\left.25^{\circ} \mathrm{C}\right)$ to represent refrigeration and room temperatures. For each sample, $25 \mu \mathrm{L}$ of diluted host strains $\left(4 \times 10^{5} \mathrm{CFU} / \mathrm{mL}\right)$ were carefully pipetted onto the surface of the meat and cabbage or into the milk samples and allowed to attach for $15 \mathrm{~min}$ at room temperature in a biosafety cabinet. This was followed by adding $25 \mu \mathrm{L}$ of diluted phages $\left(4 \times 10^{9} \mathrm{PFU} / \mathrm{mL}\right)$ per sample. For the controls, the same volume of SM buffer was used instead of the phage suspension. All samples were performed in triplicate. Bacteria and its phage were monitored by viability counting on LB plates after $0,1,2,3,4$ and 5 h of phage treatment. To quantify Salmonella, each chicken breast piece and Chinese cabbage was homogenized in $5 \mathrm{~mL}$ PBS. Salmonella were detected directly in milk samples. Salmonella were counted by pouring larger aliquots $(1 \mathrm{~mL})$ of diluted or undiluted of milk sample or the homogenates with molten LB agar on 90-mm plates. Simultaneously, the concentration of phage was determined at each of the monitored times. Phage counts were done by the agar-overlay technique. Aliquots of $100 \mu \mathrm{L}$ of serial 10 -fold dilution from the samples were mixed with $100 \mu \mathrm{L}$ host cells and $4 \mathrm{~mL}$ molten $\mathrm{LB}$ soft agar (0.6\%). The detection limits for bacteria 
or phage enumeration were $1 \mathrm{CFU} / \mathrm{Sample}$ or $10 \mathrm{PFU} / \mathrm{Sample}$ in milk samples and $5 \mathrm{CFU} / \mathrm{Sample}$ or $50 \mathrm{PFU} / \mathrm{Sample}$ in chicken breast and Chinese cabbage samples. Values less than the detection limit for chicken breast and Chinese cabbage samples were replaced with 5 CFU/Sample.

\subsection{Phage Cocktail Control of SE Mixture}

The efficacy of the phage cocktail (combination of PA13076 and PC2184) was studied on food samples (chicken breast, pasteurized whole milk and Chinese cabbage) that were experimentally contaminated with a mixture of equal numbers of Salmonella ATCC13076 and CVCC2184. The purified phage stocks of PA13076 and PC2184 were used to make a phage cocktail in SM buffer with a combined titer of $4 \times 10^{9} \mathrm{PFU} / \mathrm{mL}$. Briefly, before adding the $25 \mu \mathrm{L}$ of phage cocktail, the prepared food samples were pre-incubated with $12.5 \mu \mathrm{L} 4 \times 10^{5} \mathrm{CFU} / \mathrm{mL}$ of each SE strains and allowed to attach for $15 \mathrm{~min}$. After phages were added, samples were further incubated at $4{ }^{\circ} \mathrm{C}$ or $25^{\circ} \mathrm{C}$ for up to $5 \mathrm{~h}$. The numbers of viable Salmonella concentration were calculated as described above. The detection limits for numbers of bacteria were also the same as above.

\subsection{Determination of Phage Stability on Foods}

Twenty-five microliters of diluted phages $\left(1.6 \times 10^{10} \mathrm{PFU} / \mathrm{mL}\right)$ were inoculated directly onto the surface of the meat and cabbage or into the milk sample. These samples were then incubated at $4{ }^{\circ} \mathrm{C}$ or $25{ }^{\circ} \mathrm{C}$. The phage titers were determined at $0,5,24,48$ and $72 \mathrm{~h}$, separately. The detection limits for phage titers were the same as in Section 2.8.

\subsection{Statistical Analysis}

Bacteria and phage concentrations of each sample were determined by duplicate plating. Results are shown as mean values of the logarithm of CFU/sample and the standard deviations of the mean are indicated by error bars. Each phage-treated sample was compared to its control counterpart using one-way ANOVA. Significant differences were discriminated using Duncan's test with significance set at $p<0.05$. All data were analyzed using SPSS 16.0 (SPSS Inc., Chicago, IL, USA).

\section{Results}

\subsection{Lytic Phages Isolation and Purification}

Two new SE phages were isolated and designated as vB_SenM-PA13076 (PA13076) and vB_SenM-PC2184 (PC2184) by their ability to propagate on host strains SE ATCC13076 and CVCC2184, respectively. The bacteria present in the middle of the plaque could not form lysogen. These two phages are indeed strictly lytic. In spot tests, phages PA13076 formed clearing zones on lawns of ATCC13076 and phages PC2184 formed clearing zones on lawns of CVCC2184. Both PC2184 and PA13076 could cross-react and lyse to the other's hosts. The two phages formed round and clear zones on their own hosts, and the size of plaques were 0.5 to $1 \mathrm{~mm}$. 


\subsection{Phages Morphologies}

TEM images of phage PA13076 and PC2184 are shown in Figure 1. They all had the characteristics of a Myoviridae family (with a contractile tail). The head of PA13076 was oval and $66 \mathrm{~nm}$ in diameter. Its tail was $90 \mathrm{~nm}$ in length and $18 \mathrm{~nm}$ in diameter. PC2184 possessed an icosahedral head (diameter, $65 \mathrm{~nm}$ ) and a contractile tail (length, $106 \mathrm{~nm}$ and diameter, $17 \mathrm{~nm}$ ).
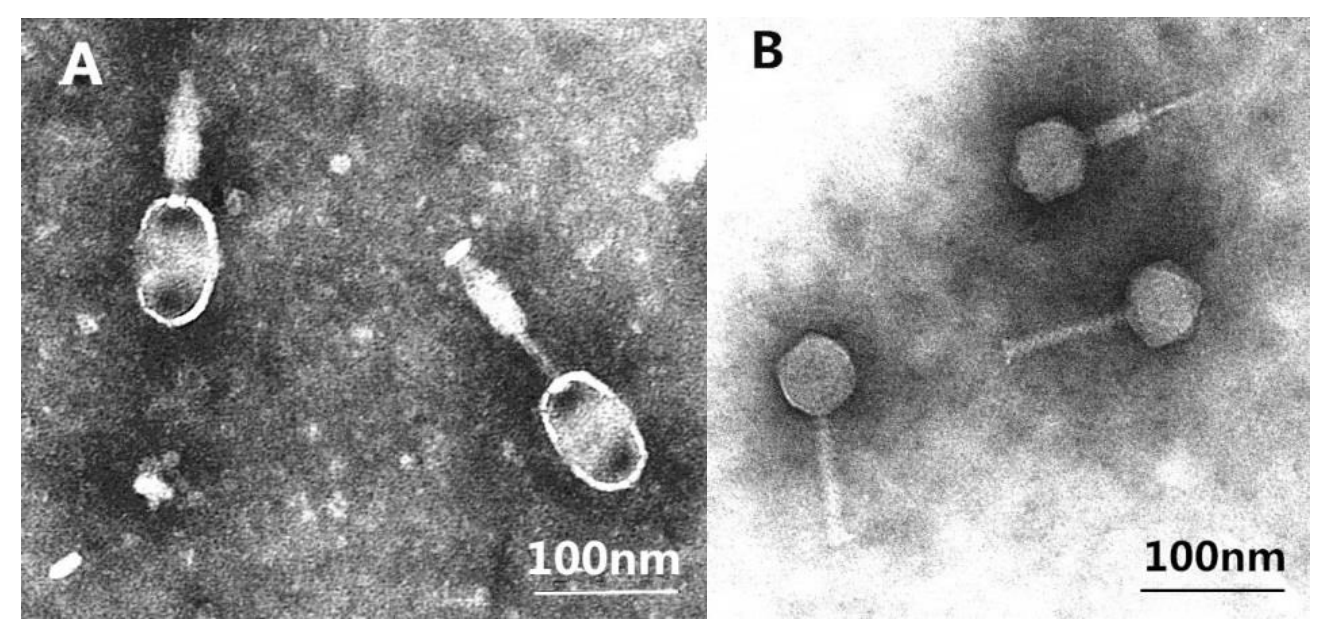

Figure 1. Transmission electron micrographs (TEM) of phage PA13076 (A) and PC2184 (B).

\subsection{Thermal and $p H$ Stability}

Phage PA13076 and PC2184 were stable between $30{ }^{\circ} \mathrm{C}$ to $50{ }^{\circ} \mathrm{C}$ for $30 \mathrm{~min}$ and $60 \mathrm{~min}$. At $60{ }^{\circ} \mathrm{C}$, there was 2-log reduction for PA13076, whereas PC2184 had only a slight reduction. PA13076 were not detectable at $70{ }^{\circ} \mathrm{C}$ and PC2184 were not detectable for $60 \mathrm{~min}$ at $80{ }^{\circ} \mathrm{C}$ (Figure 2A,B). The titers of phage were relatively stable at $\mathrm{pH} 6$ to 11 for PA13076 and at $\mathrm{pH} 5$ to 11 for PC2184. Their titers declined dramatically under lower or higher $\mathrm{pH}$ conditions (Figure 2C).

\subsection{Lytic Activity of Phages PA13076 and PC2184 on Its Host in Vitro}

Figure 3A shows the reduction of SE ATCC13076 growth compared to phage-free control $(\mathrm{MOI}=0)$ when phage were added at MOIs of $10^{2}, 10^{3}$ and $10^{4}$ to host cells initially present at $1.46 \times 10^{4} \mathrm{CFU} / \mathrm{mL}$. PA13076 achieved a peak reduction of $0.9,1.6$, and $1.8 \log$ CFU/mL after $0.5 \mathrm{~h}$, respectively. The number of viable SE ATCC13076 was reduced by about 3.5-log when treated with phage at MOI of $10^{2}$ and $10^{3}$ compared to the phage-free control after $5 \mathrm{~h}$. Moreover, the number of viable SE ATCC13076 was reduced by 5.5-log when treated with PA13076 at MOI of $10^{4}$. Figure 3B describes the same experiment using $1.23 \times 10^{4} \mathrm{CFU} / \mathrm{mL}$ of SE CVCC2184 and different MOIs of PC2184. When the highest MOI $\left(10^{4}\right)$ of PC2184 was used, SE CVCC2184 numbers were reduced dramatically compared with the control; no viable bacteria were detected by $2 \mathrm{~h}$. The number of viable Salmonella remaining at each time was dependent on the MOI used; higher MOI resulted in lower numbers of viable bacteria. 

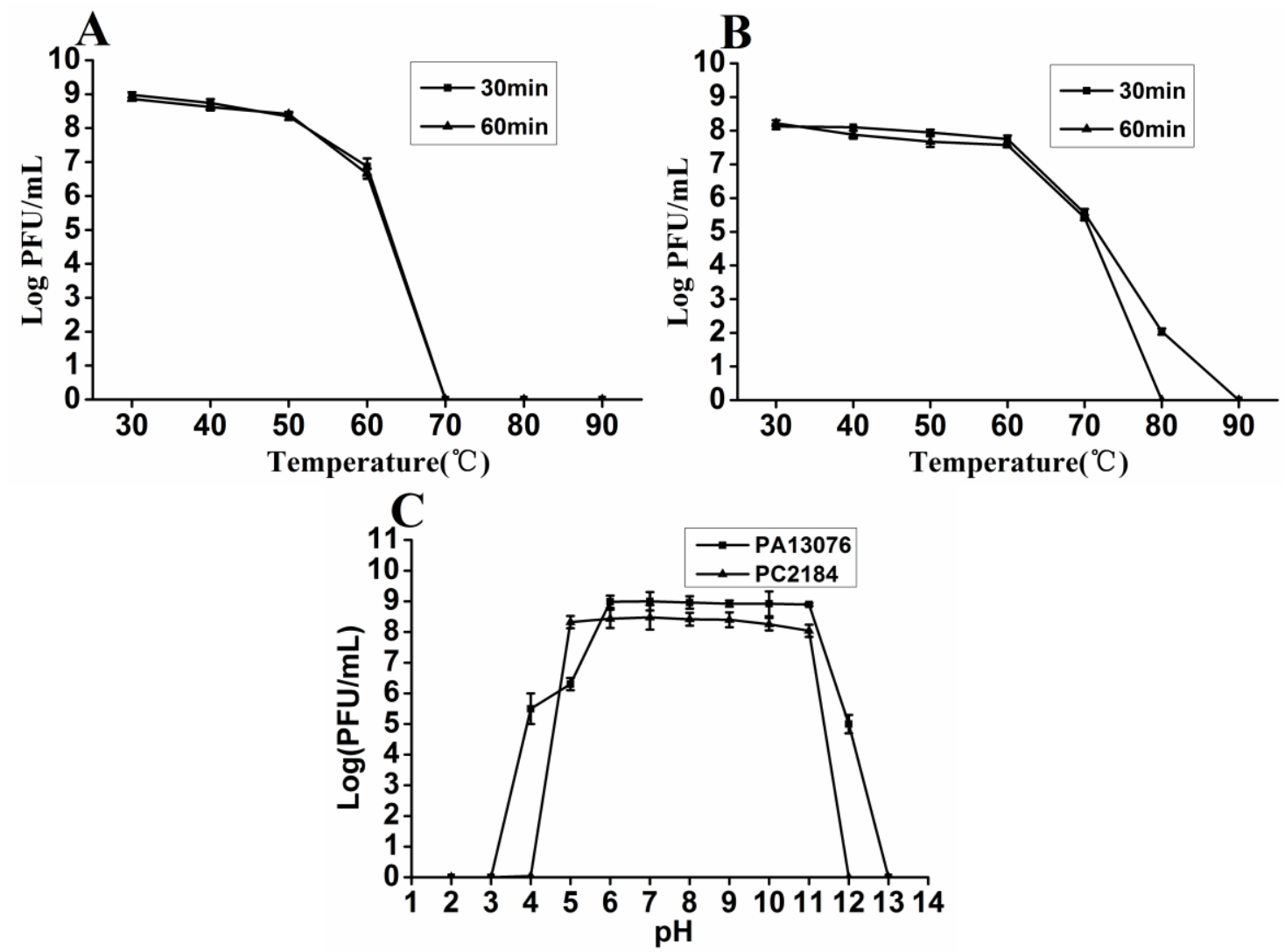

Figure 2. The thermal stability of phages PA13076 (A) and PC2184 (B); and the pH stability of phages PA13076 and PC2184 (C).
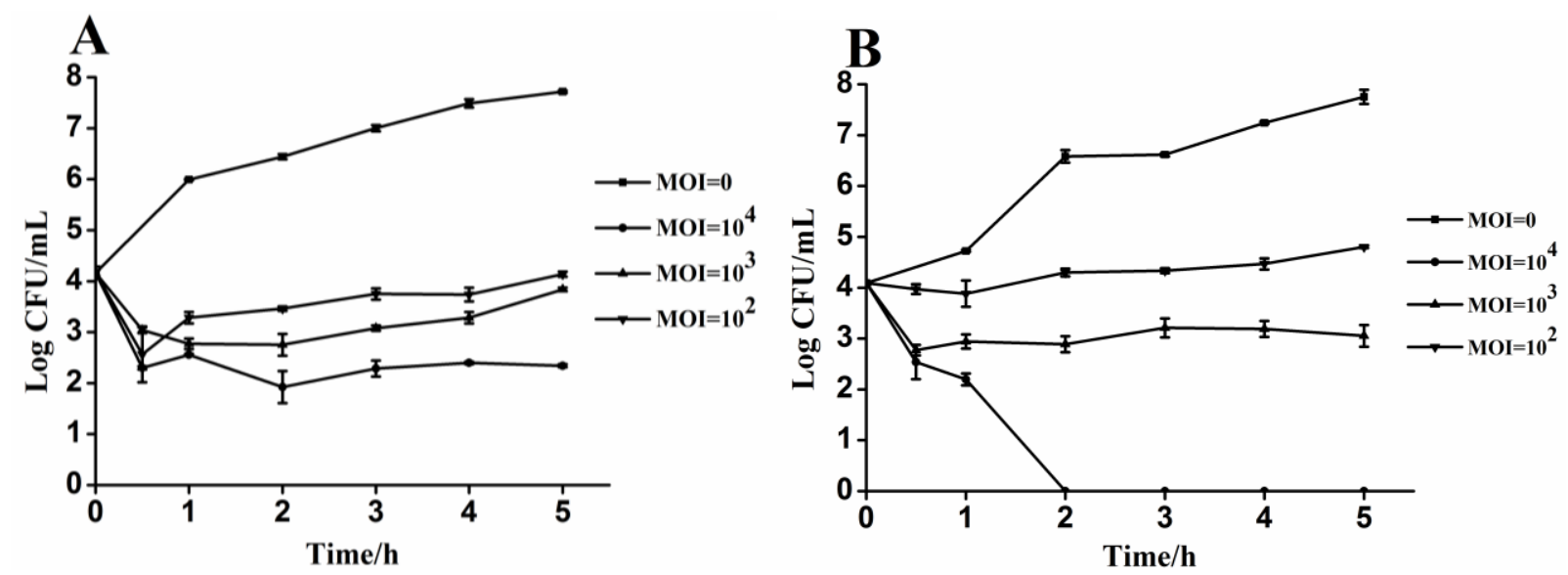

Figure 3. Lytic effects of phage PA13076 and PC2184 against the specified hosts of liquid cultures in vitro: (A) PA13076 and (B) PC2184.

\subsection{Host Ranges of Phage PA13076 and Phage PC2184}

The phage PA13076 and phage PC2184 both possessed wide host ranges. The results indicated that phage PA13076 had a lytic effect on 222 of the 311 epidemic Salmonella isolates (71.4\%), whereas PC2184 produced a lytic effect on 298 isolates (95.8\%) (Supplementary Table S1). 


\subsection{Efficacy of Individual Phage in the Bio-Control SE in Contaminated Foods}

No host organisms were isolated from uninoculated control samples. The results shown in Figures 4-6 demonstrate the effects of single phage PA13076 and phage PC2184 on SE ATCC13076 and SE CVCC2184 contamination, respectively, at 4 and $25{ }^{\circ} \mathrm{C}$ on food samples (chicken breast, pasteurized whole milk and Chinese cabbage) and the concentration of phage on the surfaces of these food products at 4 and $25{ }^{\circ} \mathrm{C}$ are also shown. The titers of phage PA13076 and PC2184 remained stable and slightly higher than the initial inoculum over $5 \mathrm{~h}$.
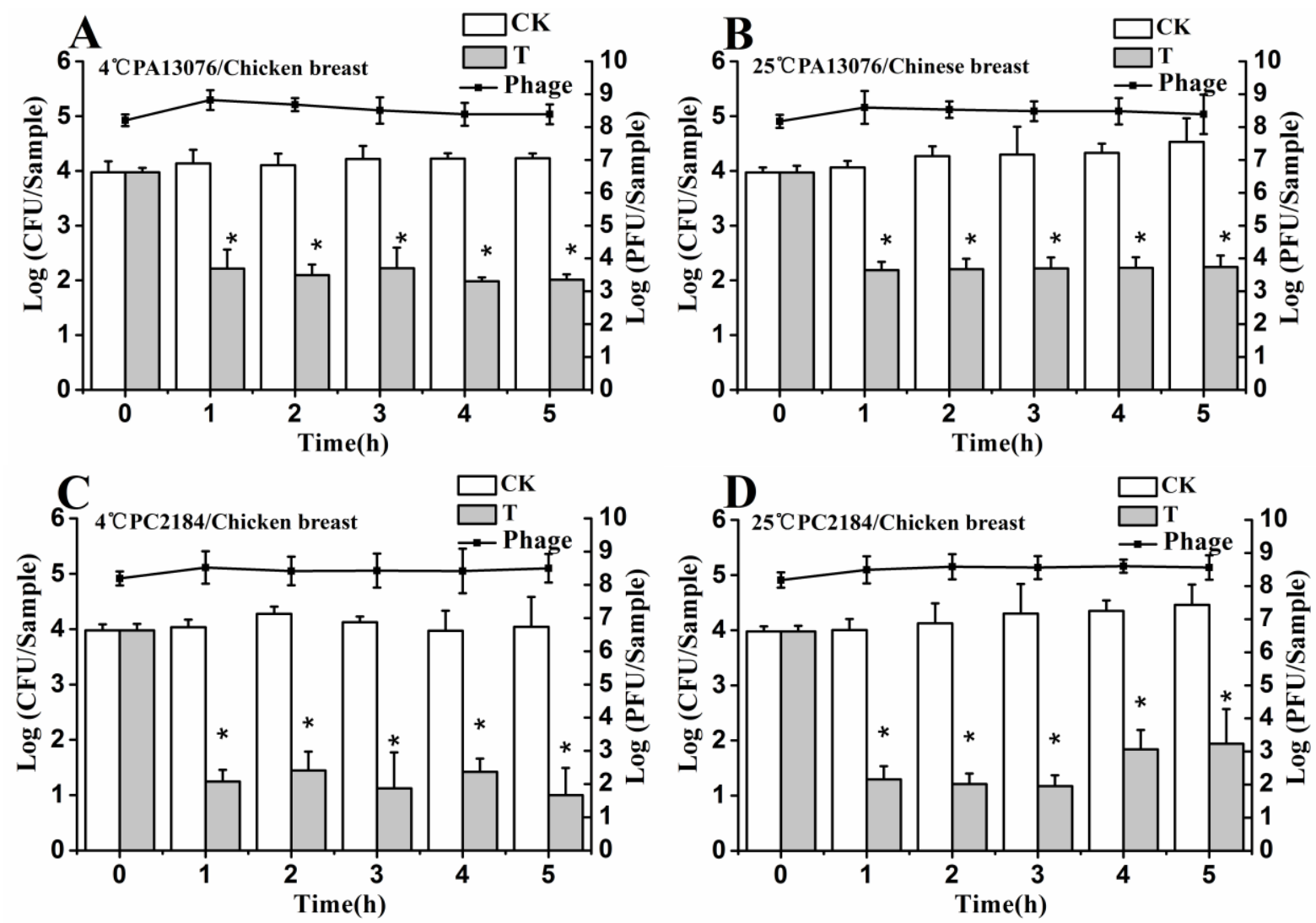

Figure 4. Effects of individual phages on growth of SE ATCC13076 and CVCC2184 on the surface of chicken breast at $4{ }^{\circ} \mathrm{C}$ and $25^{\circ} \mathrm{C}$. Each chicken breast sample was inoculated with either SE ATCC13076 (A,B) or SE CVCC2184 (C,D) $\left(1 \times 10^{4}\right.$ CFU), and phage PA13076 or PC2184 was applied $\left(1 \times 10^{8} \mathrm{PFU}\right)$ later $(\mathrm{CK}$, inoculated control without phage; $\mathrm{T}$, treated with phage). The titers of phage were also detected each sampling time (indicated in a dotted line). Date represent the mean \pm S.D. $(n=3)$, * represents $p<0.05$ (Duncan's test). 

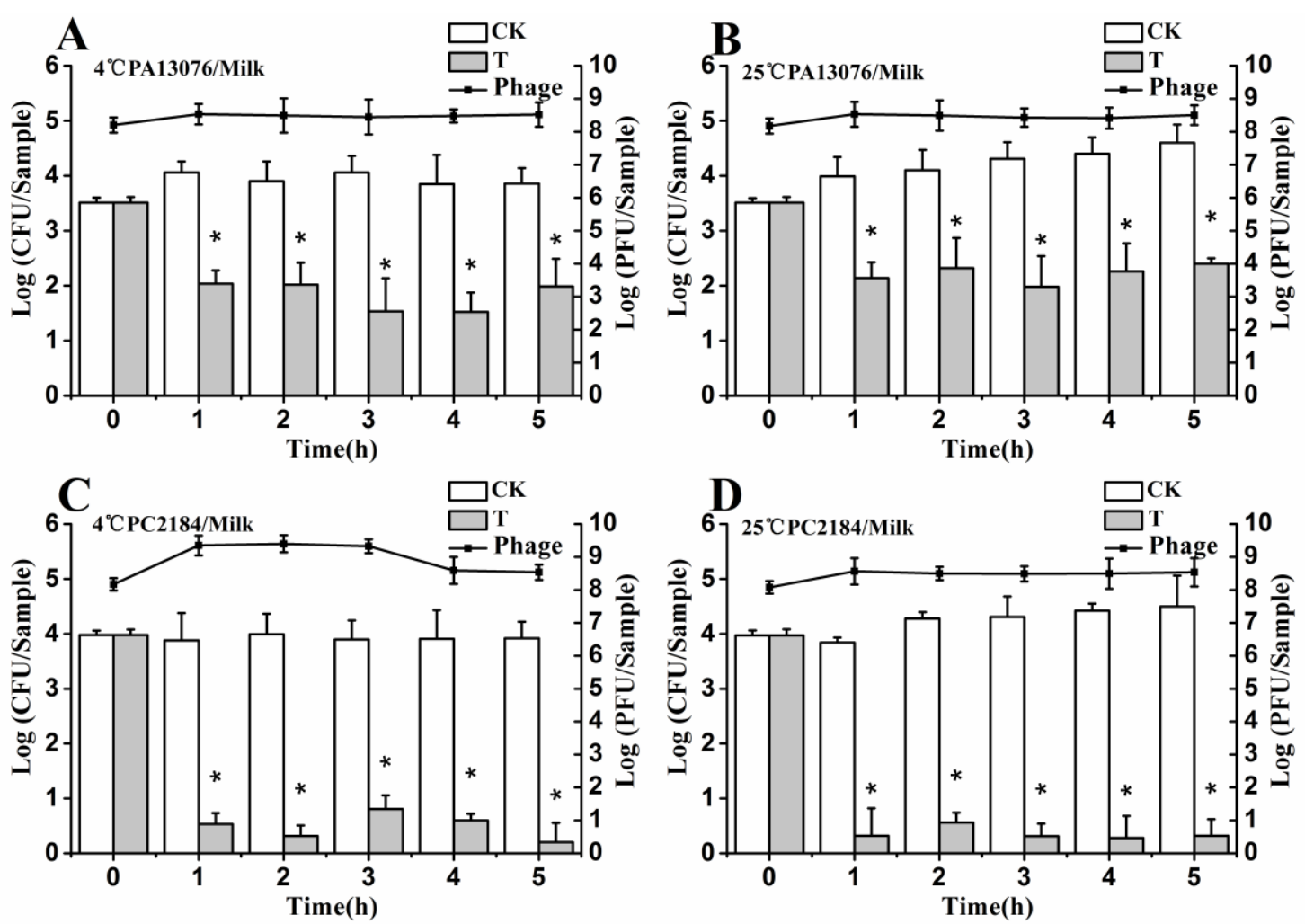

Figure 5. Effects of individual phages on growth of SE ATCC13076 and CVCC2184 in milk samples at $4{ }^{\circ} \mathrm{C}$ and $25{ }^{\circ} \mathrm{C}$. Each milk sample was inoculated with either SE ATCC13076 $(\mathbf{A}, \mathbf{B})$ or SE CVCC2184 (C,D) $\left(1 \times 10^{4} \mathrm{CFU}\right)$, and phage PA13076 or PC2184 was applied $\left(1 \times 10^{8} \mathrm{PFU}\right)$ later $(\mathrm{CK}$, inoculated control without phage; $\mathrm{T}$, treated with phage). The titers of phage were also detected each sampling time (indicated in a dotted line). Date represent the mean \pm S.D. $(n=3)$, * represents $p<0.05$ (Duncan's test).
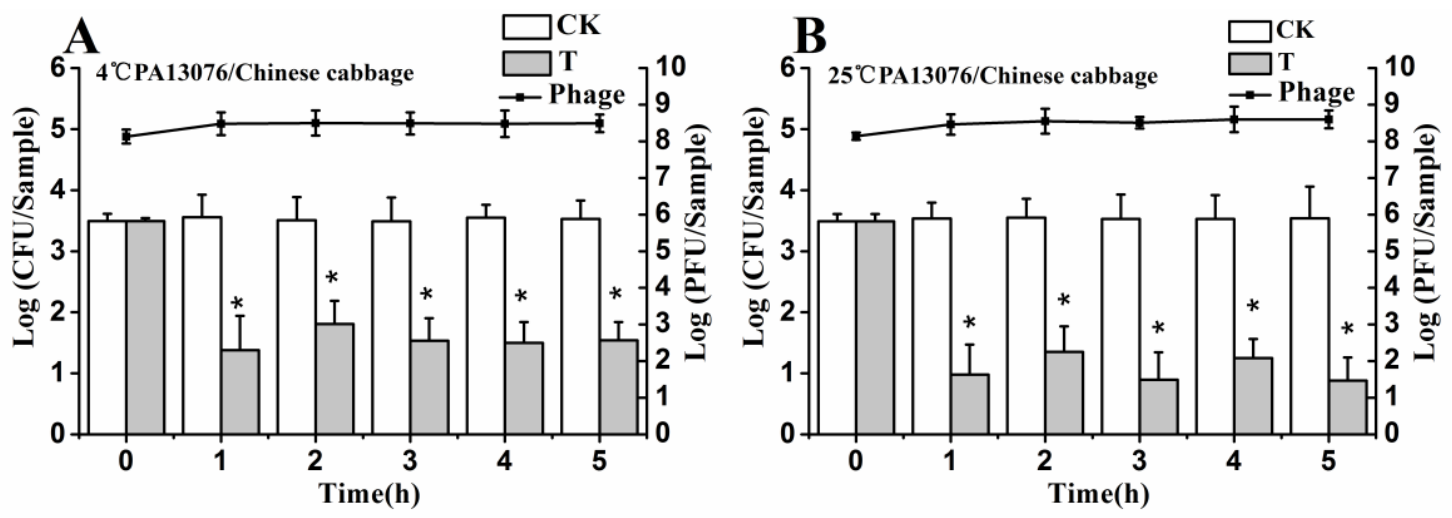

Figure 6. Cont. 

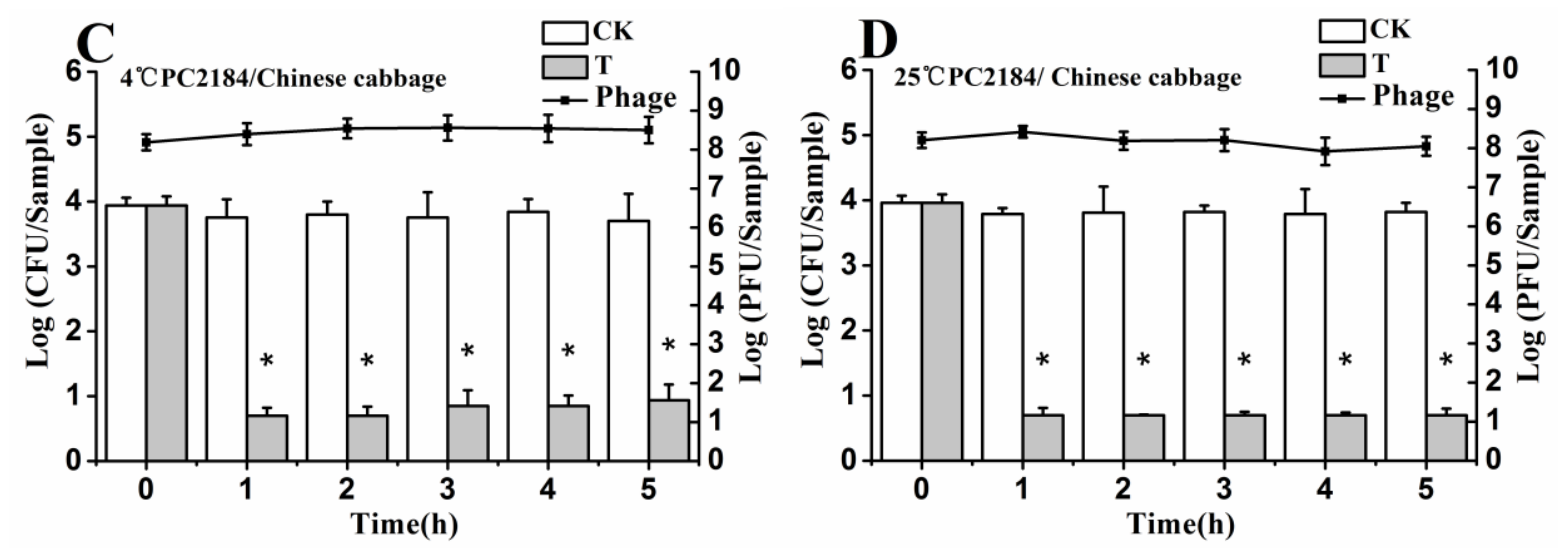

Figure 6. Effects of individual phages on growth of SE ATCC13076 and CVCC2184 on the surface of Chinese cabbage samples at $4{ }^{\circ} \mathrm{C}$ and $25^{\circ} \mathrm{C}$. Each sample was inoculated with either SE ATCC13076 (A,B) or SE CVCC2184 (C,D) $\left(1 \times 10^{4}\right.$ CFU), and phage PA13076 or PC2184 was applied $\left(1 \times 10^{8} \mathrm{PFU}\right)$ later $(\mathrm{CK}$, inoculated control without phage; $\mathrm{T}$, treated with phage). The titers of phage were also detected each sampling time (indicated in a dotted line). Date represent the mean \pm S.D. $(n=3)$, * represents $p<0.05$ (Duncan's test).

The efficacy of phage PC2184 to reduce the number of viable bacteria was clearly better than phage PA13076 at $4{ }^{\circ} \mathrm{C}$ and $25{ }^{\circ} \mathrm{C}$. PA13076 and PC2184 treated groups (T) showed significantly lower $(p<0.05) \mathrm{SE}$ counts compared with the positive control (CK) group at $4{ }^{\circ} \mathrm{C}$ and $25{ }^{\circ} \mathrm{C}$ in each of the three foods types. The most significant reductions in viable SE for the two phages were observed in pasteurized whole milk (Figure 5).

\subsection{Efficacy of Phage Cocktail on Reducing SE Mixture}

Viable counts increased slightly during incubation of SE mixture (SE ATCC13076 and SE CVCC2184) at $25{ }^{\circ} \mathrm{C}$ on chicken breast and in milk, but, at $4{ }^{\circ} \mathrm{C}$ they were stable. Bio-control by PA13076 and PC2184 cocktail resulted in a decreasing viable Salmonella counts of at least $1.65 \log$ CFU/sample (Figure 7A,B), $3.89 \mathrm{log}$ CFU/sample (Figure 7C,D) and $2.9 \log$ CFU/sample (Figure 7E,F) on the three kinds of foods in the first $1 \mathrm{~h}$, which was followed by a small amount of regrowth during the remaining incubation period at $25{ }^{\circ} \mathrm{C}$. There was almost complete elimination of viable bacteria in pasteurized whole milk at 4 and $25^{\circ} \mathrm{C}$. The effects of the phage cocktail on Chinese cabbage were better than for chicken breast. After $5 \mathrm{~h}$ at $4{ }^{\circ} \mathrm{C}$, the SE concentration was reduced by about $3.86 \log \mathrm{CFU} / \mathrm{sample}$ on Chinese cabbage and $2.5 \log \mathrm{CFU} / \mathrm{sample}$ on chicken breast relative to the initial concentration of bacteria at $0 \mathrm{~h}$. The reduction in SE counts was somewhat less on Chinese cabbage (3.0 $\log \mathrm{CFU} /$ sample) at $25^{\circ} \mathrm{C}$ after $5 \mathrm{~h}$. 

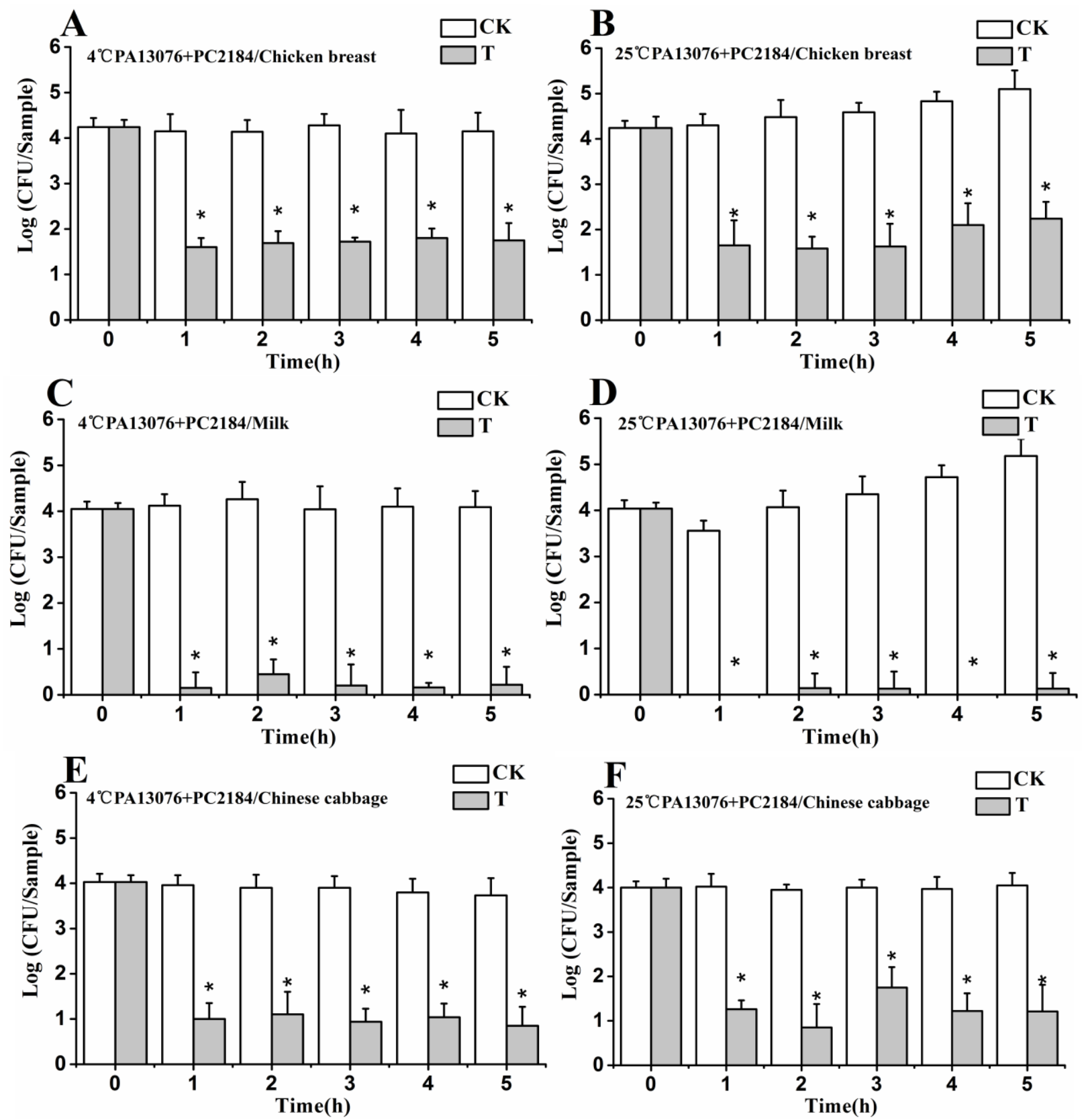

Figure 7. Efficacy of phage cocktail on reducing SE mixture treated food samples at $4{ }^{\circ} \mathrm{C}$ and $25^{\circ} \mathrm{C}$ : $(\mathbf{A}, \mathbf{B})$ chicken breast; $(\mathbf{C}, \mathbf{D})$ pasteurized whole milk; and $(\mathbf{E}, \mathbf{F})$ Chinese cabbage. Each sample was inoculated with $1 \times 10^{4} \mathrm{CFU}$ of SE mix (CK), or $1 \times 10^{4} \mathrm{CFU}$ of SE mix and $1 \times 10^{8}$ PFU of phage cocktail $(\mathrm{T})$. Date represent the mean \pm S.D. $(n=3)$, * represents $p<0.05$ (Duncan's test).

\subsection{Stability of Phage on the Treated Foods}

The concentration of phage PA13076 and phage PC2184 added to the food samples were monitored over $72 \mathrm{~h}$. In milk samples, we observed no significant loss in titers of phage PA13076 at $4{ }^{\circ} \mathrm{C}$ and $25^{\circ} \mathrm{C}$ (Figure 8C), however there was a significant loss in titers of phage $\mathrm{PC} 2184$ at $4{ }^{\circ} \mathrm{C}$ and $25^{\circ} \mathrm{C}$ at $72 \mathrm{~h}$ (Figure 8D). For phage PA13076 and PC2184 added to chicken breast, titers remained stable up to $48 \mathrm{~h}$ at $4{ }^{\circ} \mathrm{C}$ and up to $24 \mathrm{~h}$ at $25{ }^{\circ} \mathrm{C}$ (Figure 8A,B). Phage PA13076 and PC2184 all decreased about $2 \log$ 
CFU/sample and $4 \log$ CFU/sample on chicken breast at 48 and $72 \mathrm{~h}$, respectively, at $25{ }^{\circ} \mathrm{C}$. However, in Chinese cabbage (Figure 8E,F), these two phages are relatively stable up to $48 \mathrm{~h}$ at $4{ }^{\circ} \mathrm{C}$ and up to $5 \mathrm{~h}$ at $25{ }^{\circ} \mathrm{C}$.
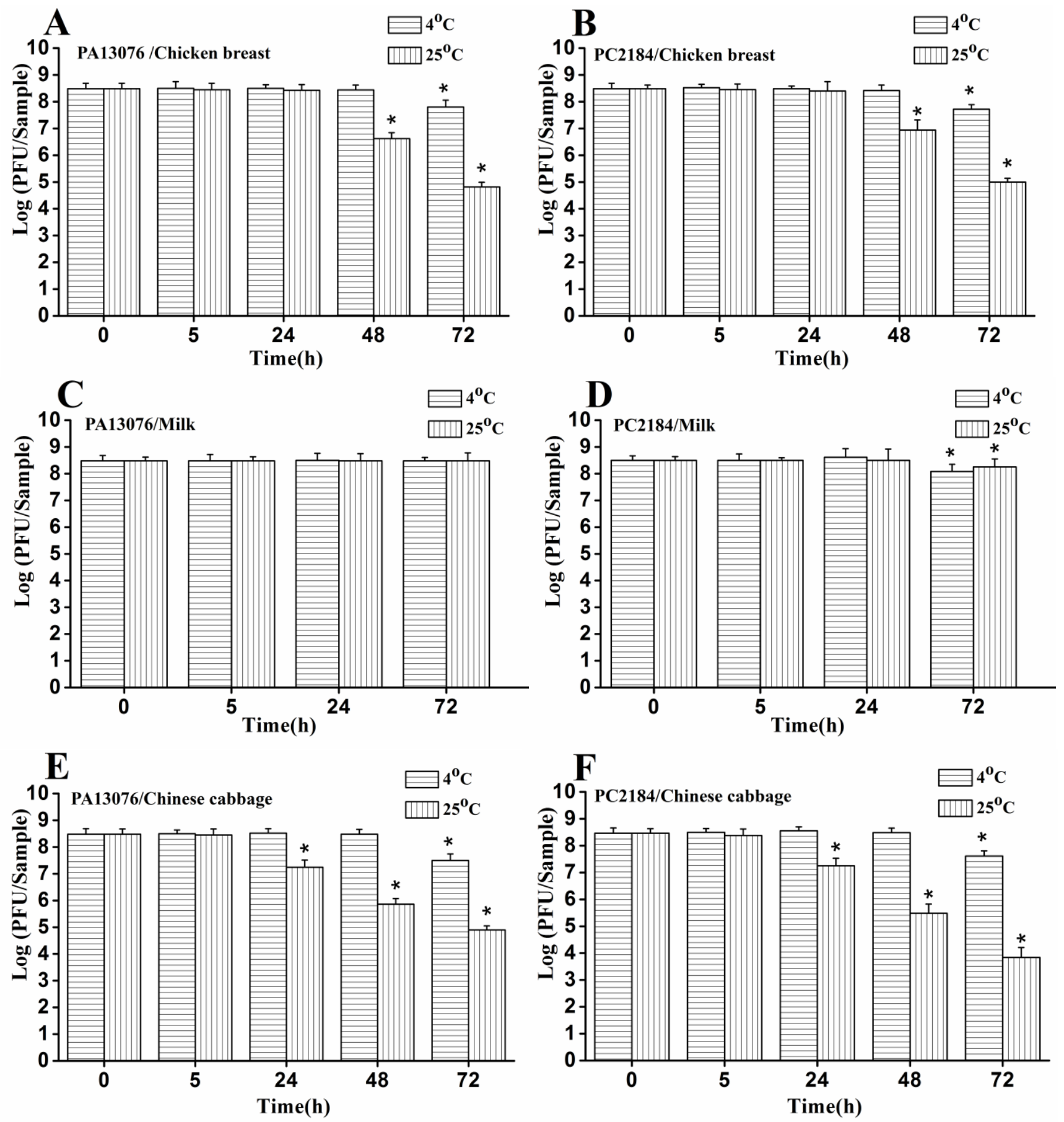

Figure 8. Stability of phage PA13076 and PC2184 over $72 \mathrm{~h}$ of incubation on the three kinds of food at $4{ }^{\circ} \mathrm{C}$ and $25{ }^{\circ} \mathrm{C}$ (the data for the milk sample at $48 \mathrm{~h}$ was lacking). Each sample was inoculated with $4 \times 10^{8}$ PFU of phage. Date represent the mean \pm S.D. $(n=3)$, * represents $p<0.05$ compared to the original phage numbers (Duncan's test). 


\section{Discussion}

In this study, two lytic bacteriophages were successfully isolated from chicken sewages and characterized as Salmonella Enteritidis phages vB_SenM-PA13076 (PA13076) and vB_SenM-PC2184 (PC2184) by international common method according to their morphologies and their host's serovar. PC2184 was very similar to the previously Salmonella phage FGCSSa1 in ultrastructure and size [22]. Although, PA13076 belonged to Myoviridae, as does PC2184, but the shape of PA13076's head is very different from other reported Salmonella phage Myoviridaes [23,24] and Siphoviruses [25,26]. Resistance to heat and $\mathrm{pH}$ are important for bio-control applications. If these characteristics are too narrow, then phages may be ineffective in actual use. The two phages were both relatively stable between $\mathrm{pH} 6$ and 9, which is compatible with the range ( $\mathrm{pH}$ 5.5-7.0) of many foods. For thermal tolerance, the two phages were rapidly inactivated if the temperature was higher than $60{ }^{\circ} \mathrm{C}$ (for PA13076) or $70{ }^{\circ} \mathrm{C}$ (for PC2184), both of the phages were rapidly inactivated. The thermal stability was similar to the Lactobacillus plantarum phage PhiJL-1 [27].

As seen in Figure 3, there were differences in the killing ability between the two phages in vitro. Phage PC2184 showed impressive killing kinetics in liquid culture, whereas phage PA13076 was not as efficient. In general, the lysis data for the two phages demonstrated that the bactericidal activity was related to the MOI. In the present study, the MOI ratio of $10^{4}$ showed the highest reduction rate of host cell counts (about 5.5-log for PA13076 and 7.0-log for PC2184). The results demonstrated that phage PC2184 killed its hosts almost completely after $2 \mathrm{~h}$ with a sufficiently high MOI $\left(10^{4}\right)$. Lytic activities of these two phages in vitro showed that a much lower ratio of $10^{2}$ or $10^{3}$ also gives good killing. Theoretically, a low MOI ratio is advantageous for the commercial feasibility of large-scale application, as it would reduce the cost of preparation, purification and application of phage products. In this assay, we also found that there was significant survival of pathogens when SE cultures were inoculated with phage PA13076 or PC2184 at MOI of $10^{2}$ and $10^{3}$. This has previously been shown for the E. coli phage $\mathrm{Mu}^{\mathrm{L}}$ [28] and the Salmonella phage FGCSSa1 [22], which did not completely lyse their hosts. Carey-Smith [22] suggested that only a subpopulation of the host was susceptible to phage infection.

Based on the above in vitro results, we designed a comprehensive study to determine whether these two phages would significantly reduce the population of Salmonella Enteritidis at high MOI $\left(10^{4}\right)$ grown on foods. Typically, relatively low numbers of Salmonella cells are present in foods (including our experiments) [29]. Commercial foods like chicken breast, pasteurized whole milk or Chinese cabbage are usually refrigerated at $4{ }^{\circ} \mathrm{C}$ or remain at room temperature $\left(25^{\circ} \mathrm{C}\right)$. Therefore, these two temperatures were chosen to test the activities of individual phages and their combination (cocktail). In the bio-control study, we demonstrated that the individual phage and the cocktail could reduce SE counts on chicken breast surface at $4{ }^{\circ} \mathrm{C}$ or $25{ }^{\circ} \mathrm{C}$ with a short contact time. In our study, SEs eliminated more counts when the phage cocktail was applied compared to individual phage treatment. Thus, the phage cocktail therapy was more efficacious. These data is consistent with numerous published papers. For example, O'Flynn et al., (2004) confirmed that a phage cocktail with MOI of $10^{6}$ could completely eliminate E. coli $\mathrm{O} 157: \mathrm{H} 7$ in seven of nine cases on meat [30]. Hooton et al., (2011) showed that a mixture of phages (PC1) was more effective at controlling Salmonella Typhimurium U288 on pig skin at a MOI of 10 or above [31]. Considering physical limitations of the solid matrix for proper dissemination of phage, 
applying more phage generally resulted in greater inactivation [32]. Our initial phage doses $\left(10^{8} \mathrm{PFU}\right)$, which ensure complete contact with Salmonella hosts $\left(10^{4} \mathrm{CFU}\right)$, caused significant reductions of Salmonella without the need for phage replicating. These kinds of therapy are called passive, which can reduce the likelihood of development of bacteria resistance [31]. Considering that much lower Salmonella concentrations were present, more phage from the beginning of the experiment is necessary to use. Because the growth of SE was greatly suppressed at $4{ }^{\circ} \mathrm{C}$, the ability of phage or phage cocktail gave more favorable results than the experiment at $25^{\circ} \mathrm{C}$.

In experiments on pasteurized whole milk, the ability of the individual phage PC2184 and phage cocktail to control SE was almost indistinguishable. In Guenther's study [32], similar results were obtained. Listeria counts rapidly dropped below detectable levels in liquid foods treated with phages, such as chocolate milk and mozzarella cheese brine, and the levels of residual bacteria were much lower than in other foods [32]. As suggested by Guenther, the greater efficacy of phages in liquid foods may the phage particles being freely suspended. Thus, the individual phage and phage cocktail treatment are likely to be a powerful bio-control method to reduce and possibly eliminate SE in the milk industry.

In recent years, vegetables have been implicated as potential vehicles of bacterial pathogens, including Salmonella [33]. In Chinese cabbage bio-control experiment, our results suggested that phage PA13076, PC2184 or the cocktail were each more effective at reducing SE on the surface of Chinese cabbage at $25{ }^{\circ} \mathrm{C}$ than at $4{ }^{\circ} \mathrm{C}$, which was opposite to the effects in chicken breast and pasteurized whole milk. This indicates that successful phage bio-control depends on the food matrix and temperature. Previous studies also found that the phage activity was sensitive to the physiological state of the host, which can be affected by growth conditions such as temperature, nutrient availability and oxygen tension [34,35]. These same studies showed that phage ECP-100 application significantly reduced the concentration of

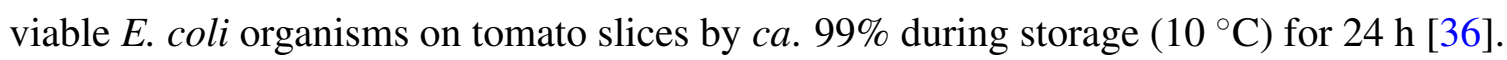

Phage PA13076 and PC2184 used in this study showed greater stable at $4{ }^{\circ} \mathrm{C}$ than at $25{ }^{\circ} \mathrm{C}$. Furthermore, they were more stable in liquid samples (pasteurized whole milk) than in chicken breast and Chinese cabbage; they remained at above $50 \%$ of the initial phage concentration. More stable phage have been reported when used in spiced chicken over $72 \mathrm{~h}$ at $4{ }^{\circ} \mathrm{C}$ [19] and phage P100 in raw salmon fillet tissue over 10 days of storage at $4{ }^{\circ} \mathrm{C}$ [37] were reported.

The results obtained in this work have shown that bacteriophage or phage cocktail has the potential to be developed as an alternative strategy to combat SE infection in food. However, it is important to ensure that no horizontal gene transduction occurs while using the phage. Moreover, isolations of new phages having a stronger lytic activity are also needed.

\section{Conclusions}

Our study has shown that bacteriophages or a phage cocktail can reduce or completely eliminate SE inoculated with $10^{4} \mathrm{CFU}$ SE in vitro and in foods. These results demonstrated that bacteriophage treatment has the potential to be developed as an alternative strategy to prevent SE infection in food safety. However, more work needs to be done to determine whether phages can be used to disinfect food products. 


\section{Acknowledgments}

We thank Matthew K. Ross (Mississippi State University) for manuscript review and professional English editing. We would like to thank G.X. Cao, G.Q. Zhu, Y.Q. Liu, Y.B. Zeng and J.S. Gong for the gift of epidemic Salmonella strains. This work was supported by a grant from the Jiangsu Province Natural Science Foundation (No. BK2012788), the Jiangsu Agricultural Science and Technology Foundation (No. CX(12)5040), and the Natural Sciences Foundation of China (NSFC No. 31402234).

\section{Author Contributions}

Hongduo Bao isolated and characterized the virulent phages used in this study. She also designed the study, analyzed the data and wrote the manuscript. Pengyu Zhang, Hui Zhang, Yan Zhou and Lili Zhang performed the bio-control experiments. Ran Wang contributed to the analysis of the results. All authors approved the final version.

\section{Conflicts of Interest}

The authors declare no conflict of interests.

\section{References}

1. Dunkley, K.D.; Callaway, T.R.; Chalova, V.I.; McReynolds, J.L.; Hume, M.E.; Dunkley, C.S.; Kubena, L.F.; Nisbet, D.J.; Ricke, S.C. Foodborne Salmonella ecology in the avian gastrointestinal tract. Anaerobe 2009, 15, 26-35. [CrossRef] [PubMed]

2. Galarce, N.E.; Bravo, J.L.; Robeson, J.P.; Borie, C.F. Bacteriophage cocktail reduces Salmonella enterica serovar Enteritidis counts in raw and smoked salmon tissues. Rev. Argent. Microbiol. 2014, 46, 333-337. [CrossRef]

3. Chai, S.J.; White, P.L.; Lathrop, S.L.; Solghan, S.M.; Medus, C.; McGlinchey, B.M.; Tobin-D’Angelo, M.; Marcus, R.; Mahon, B.E. Salmonella enterica serotype Enteritidis: Increasing incidence of domestically acquired infections. Clin. Infect. Dis. 2012, 54, S488-S497. [CrossRef] [PubMed]

4. Nesbitt, A.; Ravel, A.; Murray, R.; McCormick, R.; Savelli, C.; Finley, R.; Parmley, J.; Agunos, A.; Majowicz, S.E.; Gilmour, M.; et al. Integrated surveillance and potential sources of Salmonella enteritidis in human cases in Canada from 2003 to 2009. Epidemiol. Infect. 2012, 140, 1757-1772. [CrossRef] [PubMed]

5. Ke, B.; Sun, J.; He, D.; Li, X.; Liang, Z.; Ke, C.W. Serovar distribution, antimicrobial resistance profiles, and PFGE typing of Salmonella enterica strains isolated from 2007-2012 in Guangdong, China. BMC Infect. Dis. 2014, 14. [CrossRef] [PubMed]

6. Gorissen, B.; Reyns, T.; Devreese, M.; De Backer, P.; Van Loco, J.; Croubels, S. Determination of selected veterinary antimicrobials in poultry excreta by UHPLC-MS/MS, for application in Salmonella control programs. Anal. Bioanal. Chem. 2015, 407, 4447-4457. [CrossRef] [PubMed]

7. Hotes, S.; Traulsen, I.; Krieter, J. Salmonella control measures with special focus on vaccination and logistic slaughter procedures. Transbound. Emerg. Dis. 2011, 58, 434-444. [CrossRef] [PubMed] 
8. Milbradt, E.L.; Zamae, J.R.; Araujo Junior, J.P.; Mazza, P.; Padovani, C.R.; Carvalho, V.R.; Sanfelice, C.; Rodrigues, D.M.; Okamoto, A.S.; Andreatti Filho, R.L. Control of Salmonella Enteritidis in turkeys using organic acids and competitive exclusion product. J. Appl. Microbiol. 2014, 117, 554-563. [CrossRef] [PubMed]

9. Penha Filho, R.A.; de Paiva, J.B.; da Silva, M.D.; de Almeida, A.M.; Berchieri, A., Jr. Control of Salmonella Enteritidis and Salmonella Gallinarum in birds by using live vaccine candidate containing attenuated Salmonella Gallinarum mutant strain. Vaccine 2010, 28, 2853-2859. [CrossRef] [PubMed]

10. Kutateladze, M.; Adamia, R. Phage therapy experience at the Eliava Institute. Med. Mal. Infect. 2008, 38, 426-430. [CrossRef] [PubMed]

11. Mann, N.H. The potential of phages to prevent MRSA infections. Res. Microbiol. 2008, 159, 400-405. [CrossRef] [PubMed]

12. Goode, D.; Allen, V.M.; Barrow, P.A. Reduction of experimental Salmonella and Campylobacter contamination of chicken skin by application of lytic bacteriophages. Appl. Environ. Microbiol. 2003, 69, 5032-5036. [CrossRef] [PubMed]

13. Leverentz, B.; Conway, W.S.; Alavidze, Z.; Janisiewicz, W.J.; Fuchs, Y.; Camp, M.J.; Chighladze, E.; Sulakvelidze, A. Examination of bacteriophage as a biocontrol method for salmonella on fresh-cut fruit: A model study. J. Food Prot. 2001, 64, 1116-1121. [PubMed]

14. Whichard, J.M.; Sriranganathan, N.; Pierson, F.W. Suppression of Salmonella growth by wild-type and large-plaque variants of bacteriophage Felix $\mathrm{O} 1$ in liquid culture and on chicken frankfurters. J. Food Prot. 2003, 66, 220-225. [PubMed]

15. Carlton, R.M.; Noordman, W.H.; Biswas, B.; de Meester, E.D.; Loessner, M.J. Bacteriophage P100 for control of Listeria monocytogenes in foods: Genome sequence, bioinformatic analyses, oral toxicity study, and application. Regul. Toxicol. Pharmacol. 2005, 43, 301-312. [CrossRef] [PubMed]

16. Bigot, B.; Lee, W.J.; McIntyre, L.; Wilson, T.; Hudson, J.A.; Billington, C.; Heinemann, J.A. Control of Listeria monocytogenes growth in a ready-to-eat poultry product using a bacteriophage. Food Microbiol. 2011, 28, 1448-1452. [CrossRef] [PubMed]

17. Magnone, J.P.; Marek, P.J.; Sulakvelidze, A.; Senecal, A.G. Additive approach for inactivation of Escherichia coli O157:H7, Salmonella, and Shigella spp. on contaminated fresh fruits and vegetables using bacteriophage cocktail and produce wash. J. Food Prot. 2013, 76, 1336-1341. [CrossRef] [PubMed]

18. Patel, J.; Sharma, M.; Millner, P.; Calaway, T.; Singh, M. Inactivation of Escherichia coli O157:H7 attached to spinach harvester blade using bacteriophage. Foodborne Pathog. Dis. 2011, 8, 541-546. [CrossRef] [PubMed]

19. Zhang, H.; Wang, R.; Bao, H. Phage inactivation of foodborne Shigella on ready-to-eat spiced chicken. Poult. Sci. 2013, 92, 211-217. [CrossRef] [PubMed]

20. Bao, H.; Zhang, H.; Wang, R. Isolation and characterization of bacteriophages of Salmonella enterica serovar Pullorum. Poult. Sci. 2011, 90, 2370-2377. [CrossRef] [PubMed] 
21. Swanstrom, M.; Adams, M.H. Agar layer method for production of high titer phage stocks. Proceedings of the Society for Experimental Biology and Medicine. Soc. Exp. Biol. Med. 1951, 78, 372-375. [CrossRef]

22. Carey-Smith, G.V.; Billington, C.; Cornelius, A.J.; Hudson, J.A.; Heinemann, J.A. Isolation and characterization of bacteriophages infecting Salmonella spp. FEMS Microbiol. Lett. 2006, 258, 182-186. [CrossRef] [PubMed]

23. Santos, S.B.; Kropinski, A.M.; Ceyssens, P.J.; Ackermann, H.W.; Villegas, A.; Lavigne, R.; Krylov, V.N.; Carvalho, C.M.; Ferreira, E.C.; Azeredo, J. Genomic and proteomic characterization of the broad-host-range Salmonella phage PVP-SE1: Creation of a new phage genus. J. Virol. 2011, 85, 11265-11273. [CrossRef] [PubMed]

24. Whichard, J.M.; Weigt, L.A.; Borris, D.J.; Li, L.L.; Zhang, Q.; Kapur, V.; Pierson, F.W.; Lingohr, E.J.; She, Y.M.; Kropinski, A.M.; et al. Complete genomic sequence of bacteriophage felix O1. Viruses 2010, 2, 710-730. [CrossRef] [PubMed]

25. O’Flynn, G.; Coffey, A.; Fitzgerald, G.F.; Ross, R.P. The newly isolated lytic bacteriophages st104a and st104b are highly virulent against Salmonella enterica. J. Appl. Microbiol. 2006, 101, 251-259. [CrossRef] [PubMed]

26. Kang, H.W.; Kim, J.W.; Jung, T.S.; Woo, G.J. wksl3, a New biocontrol agent for Salmonella enterica serovars enteritidis and typhimurium in foods: Characterization, application, sequence analysis, and oral acute toxicity study. Appl. Environ. Microbiol. 2013, 79, 1956-1968. [CrossRef] [PubMed]

27. Lu, Z.; Breidt, F., Jr.; Fleming, H.P.; Altermann, E.; Klaenhammer, T.R. Isolation and characterization of a Lactobacillus plantarum bacteriophage, phiJL-1, from a cucumber fermentation. Int. J. Food Microbiol. 2003, 84, 225-235. [CrossRef]

28. Fischer, C.R.; Yoichi, M.; Unno, H.; Tanji, Y. The coexistence of Escherichia coli serotype O157:H7 and its specific bacteriophage in continuous culture. FEMS Microbiol. Lett. 2004, 241, 171-177. [CrossRef] [PubMed]

29. Guenther, S.; Herzig, O.; Fieseler, L.; Klumpp, J.; Loessner, M.J. Biocontrol of Salmonella Typhimurium in RTE foods with the virulent bacteriophage FO1-E2. Int. J. Food Microbiol. 2012, 154, 66-72. [CrossRef] [PubMed]

30. O’Flynn, G.; Ross, R.P.; Fitzgerald, G.F.; Coffey, A. Evaluation of a cocktail of three bacteriophages for biocontrol of Escherichia coli O157:H7. Appl. Environ. Microbiol. 2004, 70, 3417-3424. [CrossRef] [PubMed]

31. Hooton, S.P.; Atterbury, R.J.; Connerton, I.F. Application of a bacteriophage cocktail to reduce Salmonella Typhimurium U288 contamination on pig skin. Int. J. Food Microbiol. 2011, 151, 157-163. [CrossRef] [PubMed]

32. Guenther, S.; Huwyler, D.; Richard, S.; Loessner, M.J. Virulent bacteriophage for efficient biocontrol of Listeria monocytogenes in ready-to-eat foods. Appl. Environ. Microbiol. 2009, 75, 93-100. [CrossRef] [PubMed]

33. Spricigo, D.A.; Bardina, C.; Cortes, P.; Llagostera, M. Use of a bacteriophage cocktail to control Salmonella in food and the food industry. Int. J. Food Microbiol. 2013, 165, 169-174. [CrossRef] [PubMed] 
34. Cohen, S.S. Growth Requirements of Bacterial Viruses. Bacteriol. Rev. 1949, 13, 1-24. [PubMed]

35. Hadas, H.; Einav, M.; Fishov, I.; Zaritsky, A. Bacteriophage T4 development depends on the physiology of its host Escherichia coli. Microbiology 1997, 143, 179-185. [CrossRef] [PubMed]

36. Abuladze, T.; Li, M.; Menetrez, M.Y; Dean, T.; Senecal, A.; Sulakvelidze, A. Bacteriophages reduce experimental contamination of hard surfaces, tomato, spinach, broccoli, and ground beef by Escherichia coli O157:H7. Appl. Environ. Microbiol. 2008, 74, 6230-6238. [CrossRef] [PubMed]

37. Soni, K.A.; Nannapaneni, R. Bacteriophage significantly reduces Listeria monocytogenes on raw salmon fillet tissue. J. Food Protect. 2010, 73, 32-38.

(C) 2015 by the authors; licensee MDPI, Basel, Switzerland. This article is an open access article distributed under the terms and conditions of the Creative Commons Attribution license (http://creativecommons.org/licenses/by/4.0/). 